cut from a block 9 inches square by 6 inches in thickness. The second is mounted in a glass case on a red velvet background and is composed of a crown on either side of which are the letters " $\mathrm{W}$ D," below, the words "Royal Carriage Department, 1867." These were sawed from a plate of iron one inch in thickness.

The letters are quite artistically executed, and the sawed surfaces smooth. The experience of the department leads them to recom. mend a speed of 250 feet per minute for a band saw cutting one inch iron plates. The teeth of their saws are set and filed straight, having ten to the inch, the width is ${ }_{16}^{5}$ of an inch.

They use the hardest saw steel that can be obtained, and with soap and water as a lubricant, run the saw for four or five hours without sharpening; the latter operation requires half an hour for its completion. Any curved line can be cut in plates of the above thickness with a feed of $1 \frac{1}{2}$ inch per minute. By this system very little waste of material is incurred, and the sawed surfaces are so smooth that they require but slight after finishing. It may not be inappropriate to note that previous to Colonel Clerk's experj. ments with the band saw, Mr. Krupp used the circular saw for cutting out his steel crank axles, lubricated with soap and water, and found the expedient so much more economical than reduction by a slotting machine that he has continued the practice.-Report on Steam Engineering, Paris Exposition, 1867. W. S. Auchincloss.

\title{
TRANSMISSION OF FORCE BY BELTS AND PULLEYS.
}

\section{To the Editor of the Franklin Institute Journal.}

THE following addition to the paper published sometime since in the Journal may afford some facility in use of the results of the investigation then printed. The figures are derived from, and the final results correspond to, the figures given in Table II. of the paper.*

When the arc of contact of a belt upon the least of two pulleys which it connects is

$$
90^{\circ}\left|100^{\circ}\right| 110^{\circ}\left|120^{\circ}\right| 135^{\circ}\left|150^{\circ}\right| 180^{\circ}\left|210^{\circ}\right| 210^{\circ} \mid 270^{\circ}
$$

Then the sum of the multiplication together of the inches of diam-

$$
\text { * See Vol. LV., page 22, of this Journal. }
$$


eter of the pulley by the inches of width of the belt, by the number of revolutions per minute which equal one horse-power is

$3900|3600| 3400 \mid 320)|3000| 2825|2570| 210\}|2280| 2190$

Or to make the arc of this perfectly we give the following rule:-

To find the horse-power of 33000 pounds lifted one foot high in one minute given out by certain belt, pulley and speed-

Multiply the inches of diameter of pulley by the inches width of belt and by number of revolutions per minute, and divide the result by the numbers given in the last line of figures as relating to the contact the belt has on the smaller of its pulleys, and the quo. tient will be the number of horse-power.

Machine tools, lathes and boring tools require to be belted three times as strongly as the average are in work, to overcome occasional resistance and starting frictions.

ROBERT BRIGGS.

Gunnery Experiments. - The London Globe details some late artillery experiments which showed, that in spite of all possible care in the arrangement, the exact level of the centre being taken on the target by means of a theodolite, the shot would strike ten inches above it. Theoretically, the shot would fall by gravity, and its centre should have struck about two inches below the level. The probable explanation is, that the recoil is sensibly felt before the shot has left the gun, and that the resultant of the forces acting on the gun and carriage tends to throw the muzzle up; thus the projectile, although seemingly fired point blank, really leaves the gun at an angle. With the 12 pounder breech-loading gun this angle was found to equal about thirty minutes, while with the 9 pounder muzzle loading Indian gun it equals about thirteen minutes. The difference is probably due to the projectile taking a longer time to pass through the bore of the breech-loading gun. It may be mentioned that when the gun is swung as a pendulum and fired with its axis horizontal, the shot strikes below the level.

The Insoluble Aniline Colors may be made soluble in water. by the following process. A solution of gelatine in acitic acid is first made of about the consistence of syrup, and the colors added gradually, stirring all the time until a homogeneous paste is obtained. The mixture is then to be heated over a water-bath to the temperature of boiling water, and kept at that heat for some time.

Vol. LIX.-ThIrd SERIES.-No. 4.-APriL, 1870. 